The Journal of Animal \& Plant Sciences, 31(1): 2021, Page: 36-45

ISSN (print): 1018-7081; ISSN (online): 2309-8694

\title{
GROSS, HISTOPATHOLOGICAL, HISTOENZYMATIC AND HISTOCHEMICAL STUDIES ON INFECTIOUS BURSAL DISEASE IN BROILER CHICKENS
}

\author{
B. M. Wani ${ }^{1}$, M. M. Darzi ${ }^{1}$, S. A. Kamil ${ }^{1}$, S. Shah ${ }^{1}$, S. Adil ${ }^{2}$ and T. Ayaşan ${ }^{3 *}$ \\ ${ }^{1}$ Department of Veterinary Pathology, Faculty of Veterinary Sciences and Animal Husbandry, Shuhama, SKUAST-K, \\ Kashmir, India \\ ${ }^{2}$ Department of Livestock Production and Management, Faculty of Veterinary Sciences and Animal Husbandry, \\ Shuhama, SKUAST-K, Kashmir, India \\ ${ }^{3}$ Osmaniye Korkut Ata University, Kadirli Academy of Applied Sciences, Osmaniye, Turkey \\ *Corresponding author's email:tayasan@gmail.com
}

\begin{abstract}
Immunosuppressive diseases like Infectious Bursal Disease (IBD) required quick and precise diagnosis because of the immense economic losses associated with it. Therefore, a multi-facet diagnostic approach was used to investigate the broiler chicken affected with IBD in Kashmir, India. The full history in terms of chicken population, their age group, symptoms, morbidity, mortality and vaccination schedules were collected. The post-mortem examination of dead birds was done and pathological study was conducted on samples collected. As suggestive of the disease, bursa of Fabricius was mostly affected. Histopathologically, the lymphoid depletion, follicular necrosis, cellular infiltration, congestion and epithelial desquamation were observed in bursal follicles. Histoenzymatic examination revealed scant enzymatic activity in bursa, caeca and in alveolar epithelium of Harderian gland. Histochemically, only glandular epithelial cells and the epithelial areas with inflammatory cell infiltrations were positive for acid mucopolysaccharides. The glandular epithelium of caecum and plical epithelium of bursa were found positive for acid mucopolysaccharides among the lymphoid organs. In conclusion, the bursa of Fabricius was pathologically most affected in IBD diseased broiler chicken. The bursa was enlarged in all the groups, but however, if we compare among different groups, it was haemorrhagic with dark red discolouration in severely affected birds (probably infected with highly virulent strain) and in some group's bursa was found to be enlarged, filled with catarrhal exudate but not haemorrhagic. No bursal atrophy was found in the present study thus indicating that the disease had started recently because bursal atrophy is detected in advanced cases of IBD. Further, histoenzymatic and histochemical methods were seen to be useful in diagnosis of the IBD in broiler chicken.
\end{abstract}

Keywords: Broiler, immunosuppression, lymphoid organs, histopathology, histochemistry, histoenzymatic analysis.

https://doi.org/10.36899/JAPS.2021.1.0190

Published online August 26, 2020

\section{INTRODUCTION}

The poultry industry has achieved great significance in humans by way of providing the animal protein, besides playing a pivotal role in contributing to the national economy (Nnadi and George, 2010). In India, among agricultural sectors, broiler chicken production has witnessed a tremendous growth rate of 10 $12 \%$ per year (as against $2.5 \%$ of whole agriculture) during the last 25 years with annual production of 3.8 million tonnes (Kotaiah, 2016). Despite this enormity in growth rate, birds get predisposed to various diseases which hamper their growth rate, feed conversion efficiency and increases their mortality, thereby affecting the profitability of a poultry enterprise (Siddique et al., 2008; Bell, 2009). Since, most of the poultry farms in Kashmir are either of small or medium sized, the disease affects the profitably (Itooet al., 2014). The immunosuppressive diseases are highly threatful as compared to other poultry diseases owing to their direct effect on productivity, susceptibility to secondary bacterial, parasitic diseases and have been found to be the main culprits behind vaccination failures. The Infectious bursal disease (IBD) is an extremely contagious acute viral disease of growing chicken. The causative agent of this disease is a member of genus Avibirnavirus belonging to family Birnaviridae which has 2 serotypes (serotype 1 and serotype 2) with serotype 1 as pathogenic (Lukert and Saif, 2003). This virus has high affinity for lymphoid tissue with bursa of Fabricius as site of predilection.

In highly immune suppressed birds, this virus induces apoptosis in bursa of Fabricius, thereby resulting in depletion of B-cells (Withers et al., 2005). Depending on the bird age, two forms of this disease are seen in birds as acute and subclinical forms (immunosuppressive forms) (Singh et al., 2015). This disease is among the frequently observed lymphocytolytic diseases resulting in immunosuppression of birds (Zahid et al., 2016). Symptoms like weakness, depression, dehydration, 
swollen and blood stained vent and watery diarrhoea are observed (Islam and Samad, 2004).

Because of the threat to economy, this disease warrants early and prompt diagnosis. In view of this, an effort was made to study in early diagnosis of IBD disease by gross examination, histopathological, histoenzymatic and histochemical methods in broiler chicken.

\section{MATERIALS AND METHODS}

The disease was investigated in one of the districts of Kashmir valley named Ganderbal. The disease was diagnosed after necropsy of dead birds and samples were collected and processed in the Division of Veterinary Pathology (SKUAST-Kashmir). The full history in terms of chicken population, their age group, symptoms, morbidity mortality, feeding practices and vaccination schedules were collected. The post-mortem examination of dead birds was done and pathological study was conducted on samples collected.

The birds examined consisted of different age groups as follows:

Group I: The samples were taken from broiler flock of 18 days age group. The flock comprised of about 4000 chickens, and all were vaccinated against IBD with vaccine IV-95 on $13^{\text {th }}$ day. The owner reported an average mortality of 25 chicks during the initial 2 days of disease.

Group II: This group comprised chickens of 21 days of age group taken from commercial broiler flock with a total strength of 3000 birds. The vaccination (Live vaccine- Intermediate Plus) had been done at 13 day. Mortality of 3-4 chicks was noted during last 4-5 days of sample collection.

Group III: In this group, a flock of 2000 broiler chickens showing concurrent infection of IBD and coccidiosis was selected. The affected chickens were 23 days old and all were vaccinated against IBD using MB strain on $13^{\text {th }}$ day. A mortality of 150 chicks was observed during the last two days.

Group IV: This group comprised of a broiler flock of 2500 of 25 days of age. Vaccination was done by using Intermediate strain at 13 days.

Group V: A total of 3000 broiler chickens of 27 days of age were examined. All were vaccinated against IBD on $13^{\text {th }}$ day using MB strain. A mortality of 46 chicks was observed during the last two days.

\section{Pathological examinations}

Gross pathology: Detailed examination of broiler chicken was done and particularly the lesions of lymphoid organs (bursa of Fabricius, bone marrow, thymus, spleen, caecal tonsils and Harderian gland) were recorded.

Histopathology: From various lymphoid organs (bursa of Fabricius, bone marrow, thymus, spleen, caecal tonsils and Harderian gland), representative tissue samples were obtained and kept in 10\% formalin. They were then processed for histopathological examination by routine paraffin embedding technique. The sections $(5 \mu$ thin $)$ were then stained with Haris' Haematoxylin and Eosin (Luna, 1968).

Histochemistry: Histochemical examination of various lymphoid organs (bursa of Fabricius, bone marrow, thymus, spleen, caecal tonsils and Harderian gland) was done for presence of Acid \& Neutral Mucin by Combined Alcian Blue PAS stain (Bancroft and Gamble, 2002). The Alcian blue ( $\mathrm{pH} 7$ ) was used for immersion of the tissue sections, followed by heating at $900 \mathrm{~W}$ for 45 seconds in microwave. The sample was then allowed to stand in solution for 5 minutes. Afterwards, the sections were washed for 5 minutes in running tape water and rinsed in distilled water. Thereafter, immersion in $0.5 \%$ periodic acid for 5 minutes was done. Following this, the Schiff's reagent was used for dipping of slides, which were then heated in microwave at $900 \mathrm{~W}$ for 45 seconds and allowed to stand for 5 minutes. Thereafter, the slides were again washed for 5 minutes in running tape water and rinsed in distilled water. The haematoxylin was then used for counter staining, acid alcohol for differentiation and ammonia water for bluing. Finally, the dehydration, clearing and mounting in DPX was done.

Histoenzymatic studies: For the presence of any alkaline phosphatase and acid phosphatase in tissue samples of lymphoid organs, $3 \mathrm{~mm}$ thick slices of fresh specimens were used and around $3 \mathrm{~mm}$ thick slices were cut and kept at a temperature of $-20^{\circ} \mathrm{C}$. Afterwards, the chilled tissue slices were fixed at $4^{\circ} \mathrm{C}$ for $24 \mathrm{hrs}$ in 2 to 3 changes of acetone given after every three hour interval. Gomori's Calcium Cobalt method was used for demonstration of Alkaline phosphatase and Gomori's Lead Phosphate method for Acid phosphatase (Gurr, 1958).

\section{RESULTS}

Gross pathology: Group I: The lesions on necropsy were mainly confined to bursa of Fabricius which was enlarged, severely haemorrhagic with dark red discolouration (Fig. 1). The caecal tonsils of the birds were slightly enlarged (Fig. 2), however no significant change was observed in Harderian gland, spleen and bone marrow.

Group II: The bursa was slightly enlarged and oedematous (Fig. 3). The thymus was slightly enlarged. No significant gross changes were found in caecal tonsils, Harderian gland and bone marrow. 
Group III: The typical pectoral muscle haemorrhages associated with IBD were observed (Fig. 4), bursa was enlarged and having severe petechial and ecchymotic haemorrhages resulting in complete discolouration from red to blackish red (Fig. 5). The caecal tonsils and caecum were enlarged and haemorrhagic (Fig. 6). The spleen and thymus were slightly enlarged and congested. No detectable gross lesions were noted in Harderian gland and bone marrow.

Group IV: Necropsy of the dead birds revealed that the bursa was enlarged, oedematous and the plicae surface was covered with catarrhal exudate (Fig. 7). However, in other lymphoid organs there was no significant change. Group V: The birds were reluctant to move with ruffled feathers, closed eyes and soiled vent (Fig. 8). Again bursa of Fabricius was highly affected and was enlarged, oedematous and haemorrhagic (Fig. 9). It was filled with yellowish caseous material. The thymus was not much enlarged but was congested. (Fig.10). However, in other lymphoid organs there was no significant change.

Histopathology: Group I: Lymphoid depletion, follicular necrosis, cellular infiltration, congestion and epithelial desquamation were observed in bursal follicles (Fig. 11). Harderian gland revealed alveolar narrowing, slight lymphoid depletion and epithelial desquamation (Fig. 10). The caecal tonsil and thymus revealed lymphoid depletion. The spleen revealed cellular infiltration, congestion and lymphoid depletion in the cortical area of the lymphoid follicle (Fig. 13).

Group II: The bursa showed mild lymphoid depletion, cellular infiltration and congestion. Thymus showed congestion and mild depletion (Fig. 14). Caecal tonsil revealed cellular infiltration and mild lymphoid depletion (Fig. 15). Harderian gland revealed lymphoid depletion and epithelial desquamation.

Group III: In this group severe necrosis, disorganization, depopulation and deposition of

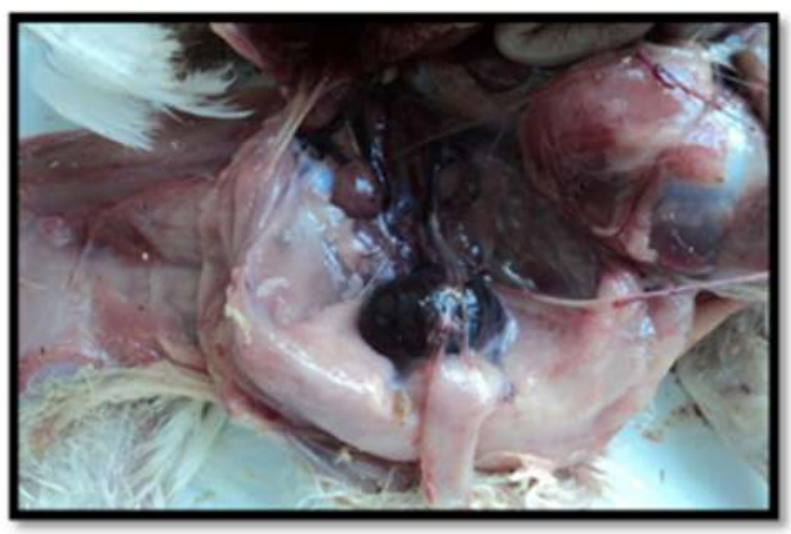

Figure 1. Enlarged and dark red discolouration of bursa in IBD infected broiler chicken eosinophilic material were observed in the bursal follicles (Fig. 16). In thymus congestion, mild depletion in cortex and necrosis was present. Spleen showed lymphoid depletion in white pulp (Fig. 17). Caecal tonsils revealed depletion and necrotic changes in the lymphoid follicle. Harderian gland revealed alveolar narrowing and congestion.

Group IV: Mild to moderate lesions in bursa were found like depletion of lymphocytes from the cortical area, congestion and infiltration of inflammatory cells. However, in other lymphoid organs there was no significant change except slight depletion of lymphoid cells in certain areas.

Group V: In this group, follicular haemorrhages, cellular infiltration and lymphoid cell depletion was observed in bursa of Fabricius (Fig. 18). In thymus and caecal tonsils, there was congestion and cellular depletion. The lymphoid cell depletion was noticed in certain areas of white pulp in spleen and in Harderian gland, plasma cell depletion was observed.

Histoenzymatic study: Staining of duplicate sections from lymphoid organs for acid phosphatase revealed scant enzymatic activity in bursa, caeca and in alveolar epithelium of Harderian gland. However, the tissue sections stained for alkaline phosphatase revealed mild reaction in inflammatory zone around the epithelial region of bursa, caecal tonsils and Harderian gland, with no enzyme activity observed in other lymphoid organs.

Histochemistry: In all the IBD infected groups, the histochemical examination revealed that only glandular epithelial cells and the epithelial areas with inflammatory cell infiltrations were positive for acid mucopolysaccharides. Among the lymphoid organs, glandular epithelium of caeca (Fig. 19), plical epithelium of bursa (Fig. 20) and Harderian gland alveolar epithelium (Fig. 21) were seen positive for increased acid mucopolysaccharides.

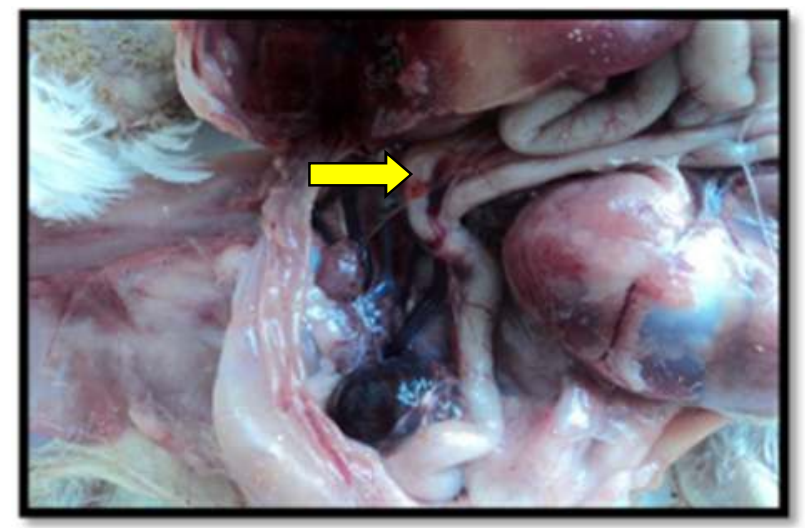

Figure 2. Swollen caecal tonsils (arrow) and dark red discolouration of bursa in IBD infected broiler chicken 


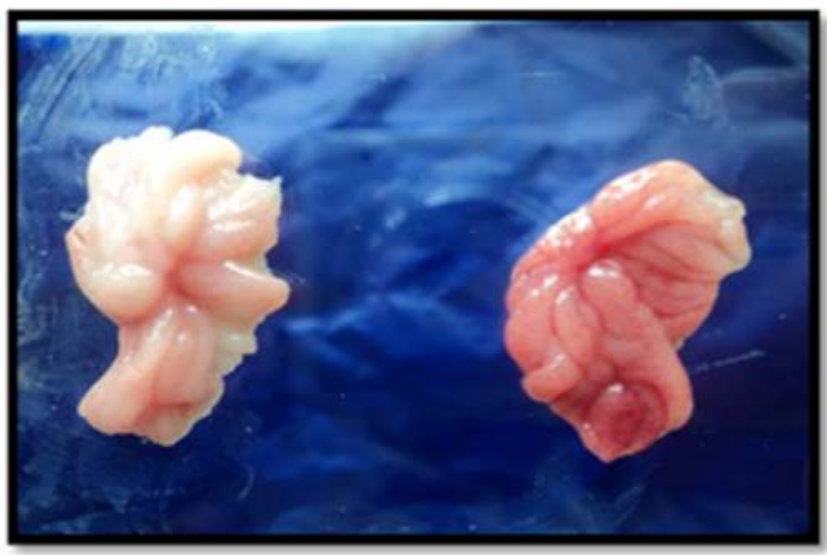

Figure 3. Bursa slightly enlarged, oedematous and congested in IBD infected broiler chicken.

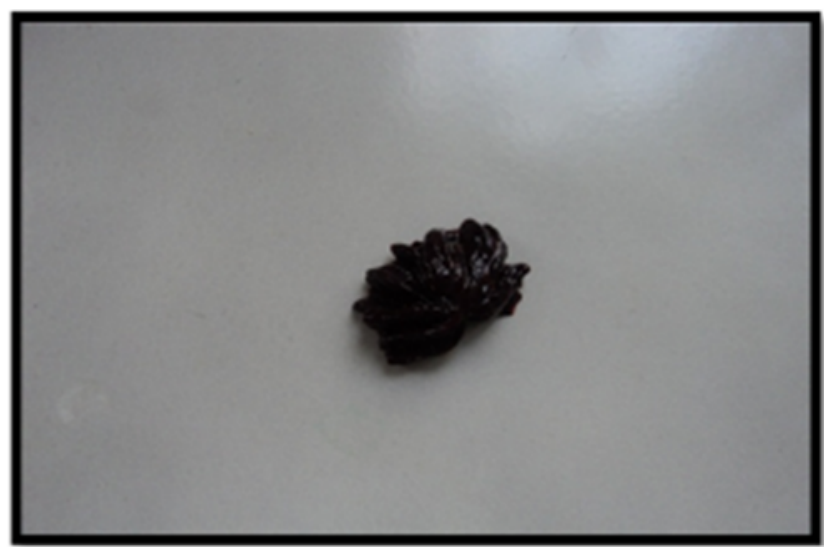

Figure 5. Blackish red discoloration of bursa in broiler chicken affected with mixed infection of IBD and Coccidiosis

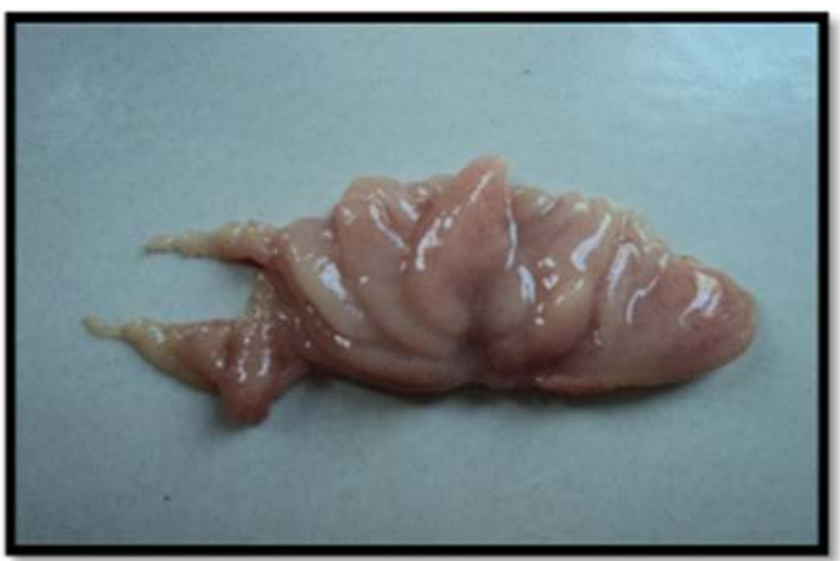

Figure 7. Bursa enlarged, oedematous and the plical surface covered with catarrhal exudate in IBD infected broiler chicken

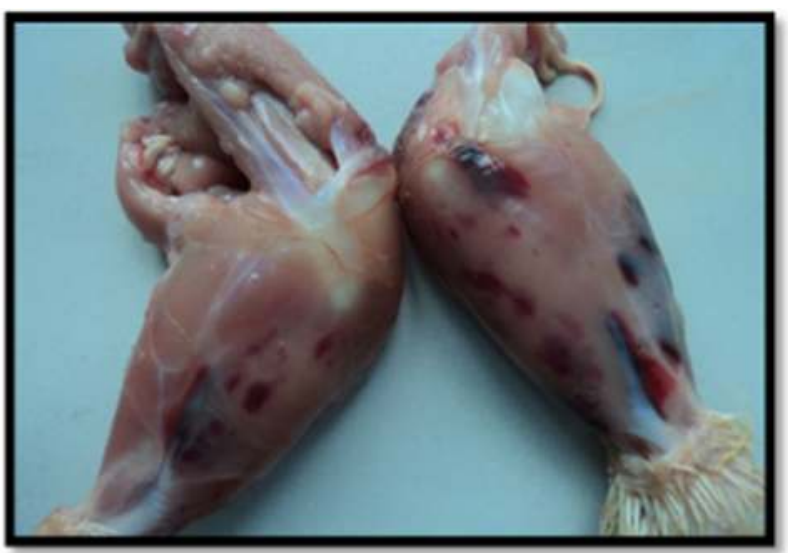

Figure 4. Haemorrhages in the thigh muscles of broiler chicken affected with mixed infection of IBD and Coccidiosis.

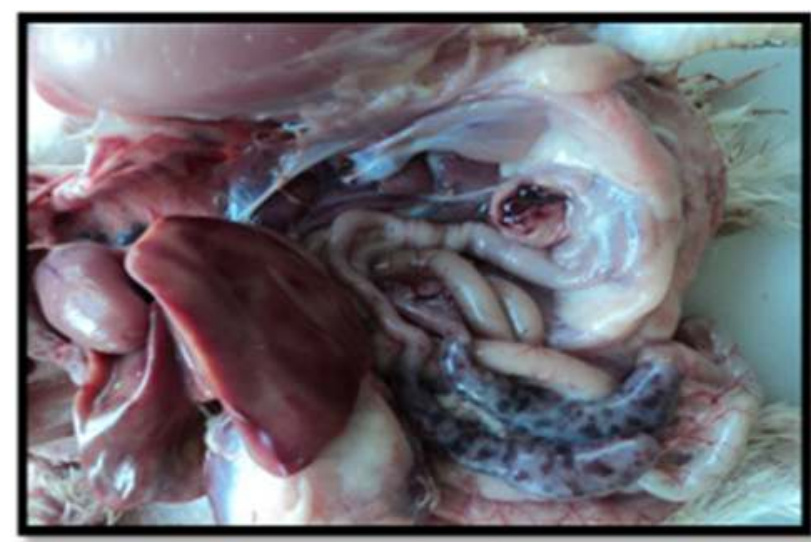

Figure 6. Enlarged caecal tonsils, haemorrhages on caecum and bursa of Fabricius in a broiler chicken affected with mixed infection of IBD and Coccidiosis

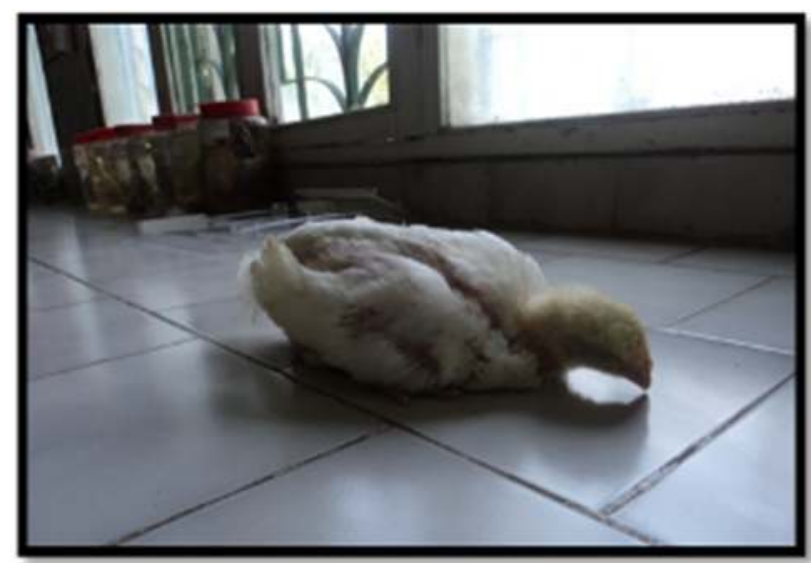

Figure 8. IBD affected chickens were reluctant to move, had ruffled feathers and closed eyes 


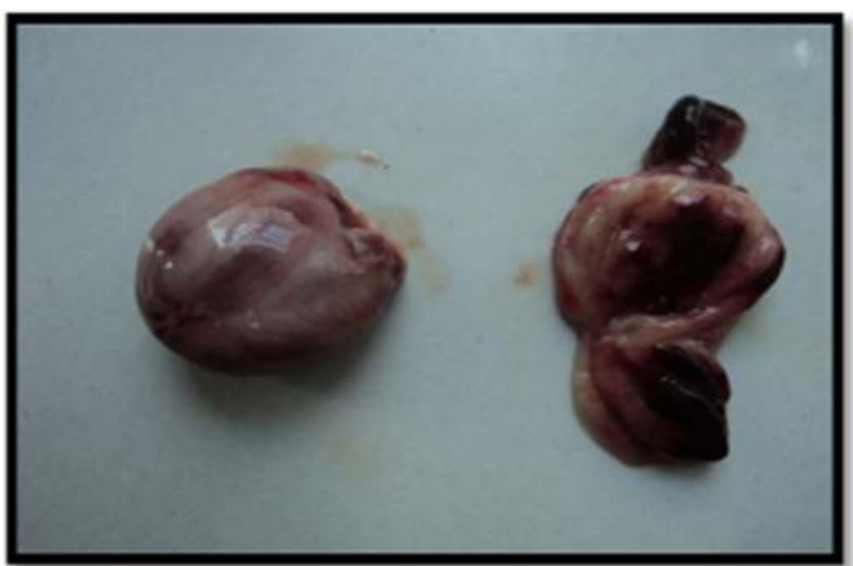

Figure 9. Bursa enlarged, oedematous and haemorrhagic in IBD affected broiler chicken

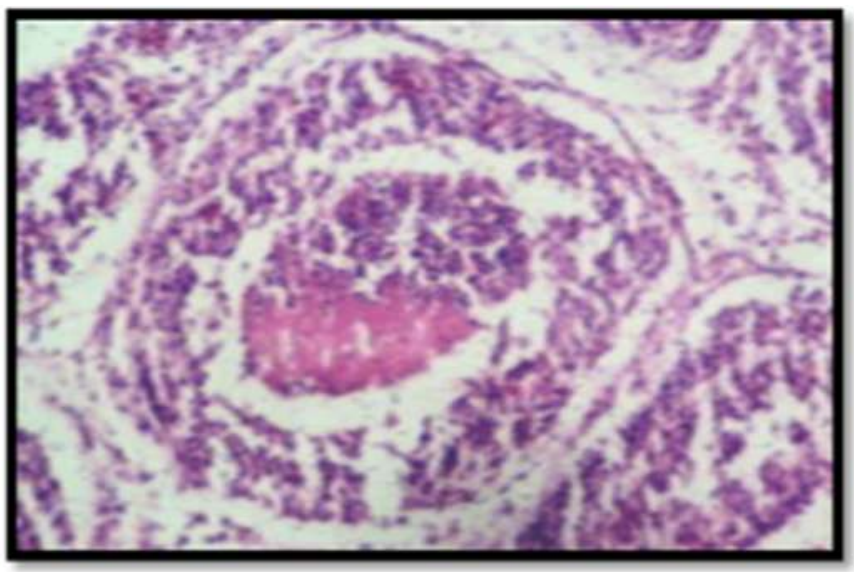

Figure 11. Section of bursa of Fabricius of IBD affected broiler chicken revealing cellular infiltration, necrosis and lymphoid depletion HE. x600

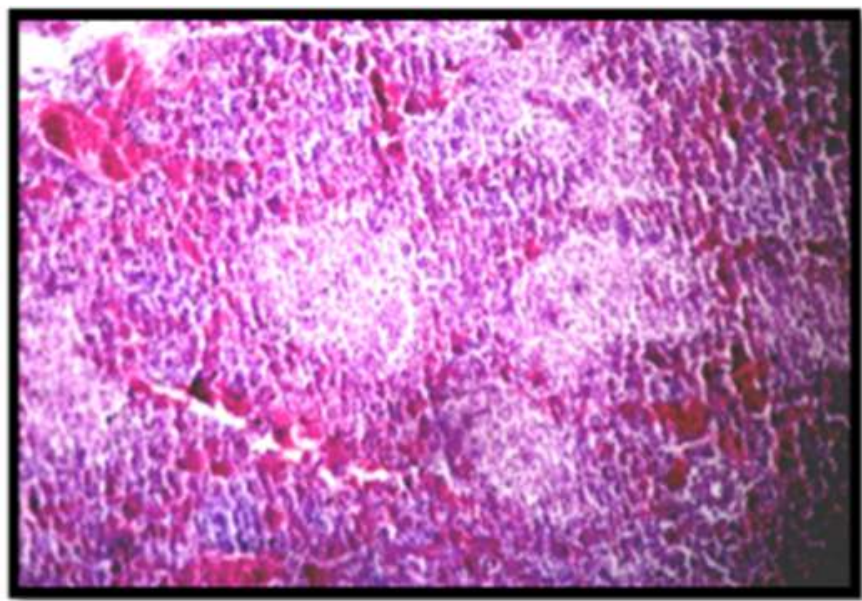

Figure 13. Section of spleen of a broiler chicken affected with IBD revealing congestion and lymphoid depletion in the cortical area of the lymphoid follicle HE. x300

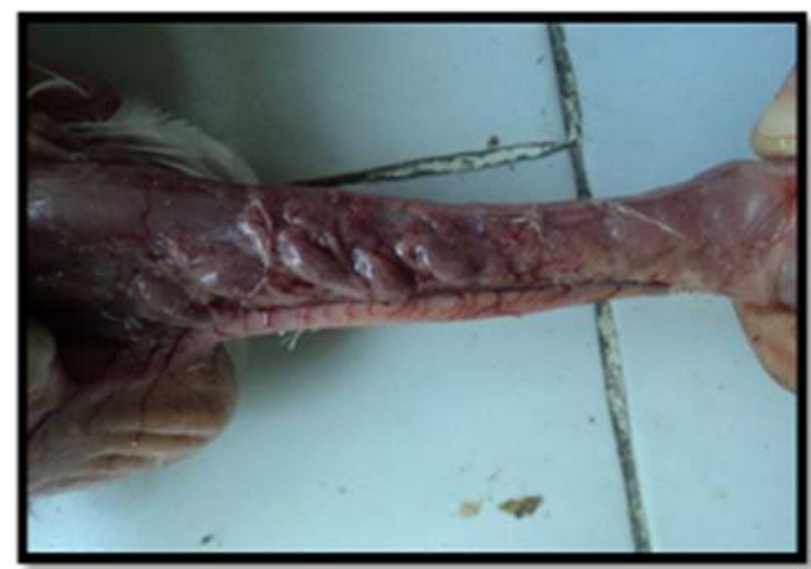

Figure 10. Enlarged and slightly congested thymus in IBD affected broiler chicken

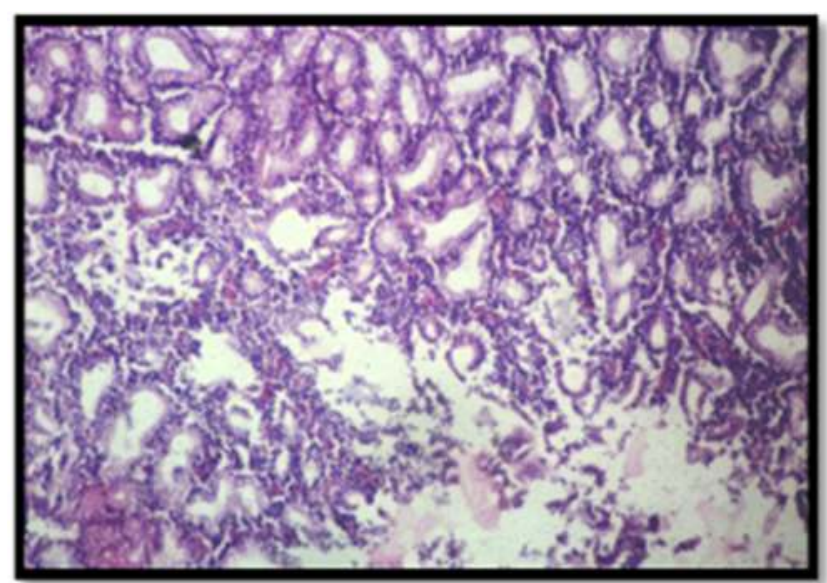

Figure 12. Section of Harderian gland of a broiler chicken affected with IBD revealing alveolar narrowing, lymphoid depletion and epithelial desquamation. HE. x600

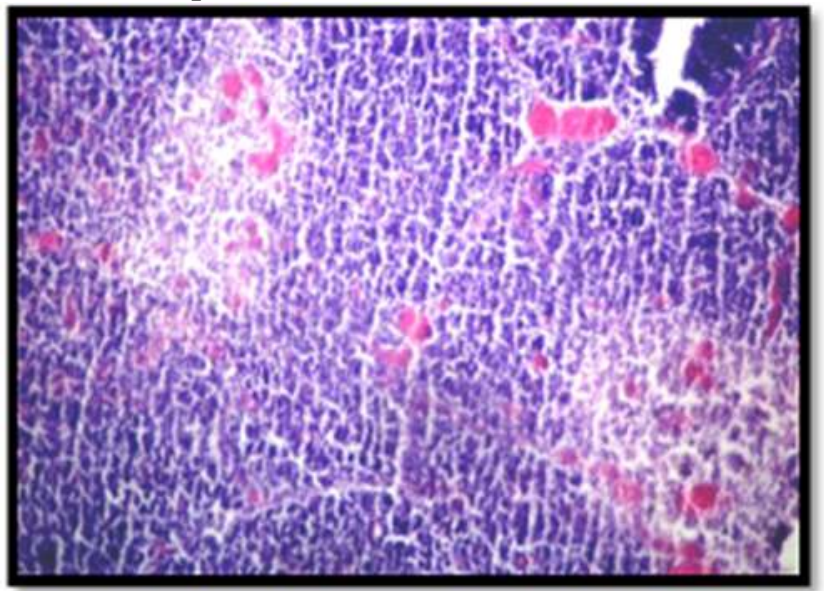

Figure 14. Section of thymus of a broiler chicken affected with IBD revealing congestion and mild lymphoid depletion. HE. x300 


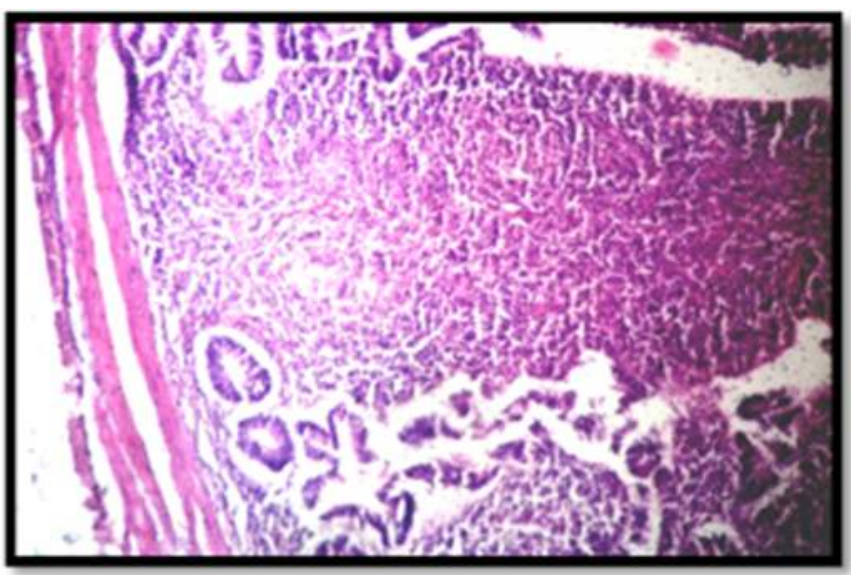

Figure 15. Section of caecal tonsil of a broiler chicken affected with IBD showing cellular infiltration and mild lymphoid depletion in lymphoid nodule. HE. $x 300$

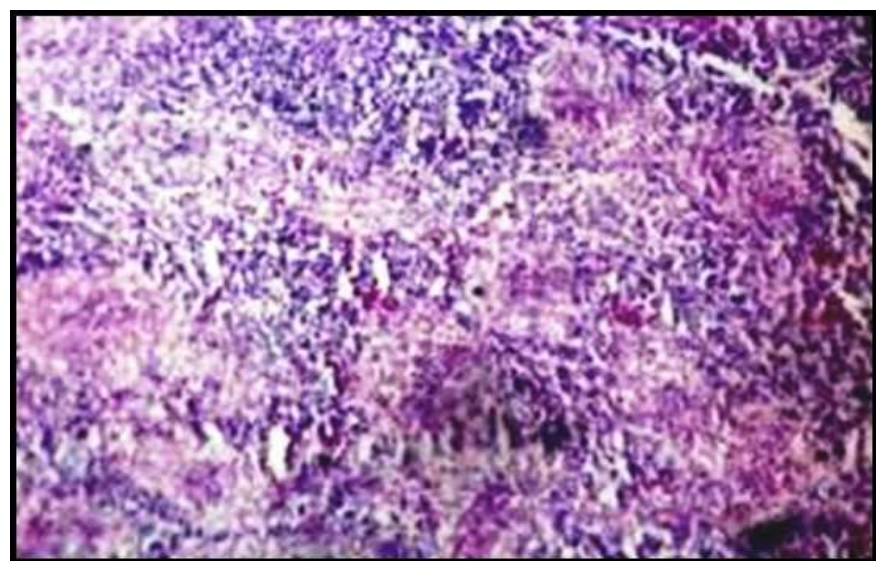

Figure 17. Section of spleen of a broiler chicken affected with mixed infection of IBD and Coccidiosis revealing mild lymphoid depletion in white pulp HE. $x 300$

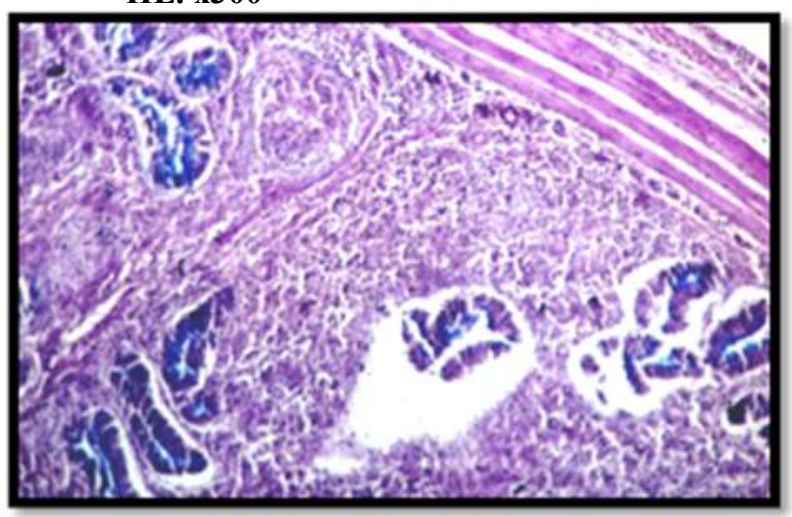

Figure 19.: Section of caecal tonsil of a broiler chicken affected with IBD revealing the glandular epithelium positive for acid mucopolysaccharides. Combined Alcian blue PAS. $x 300$

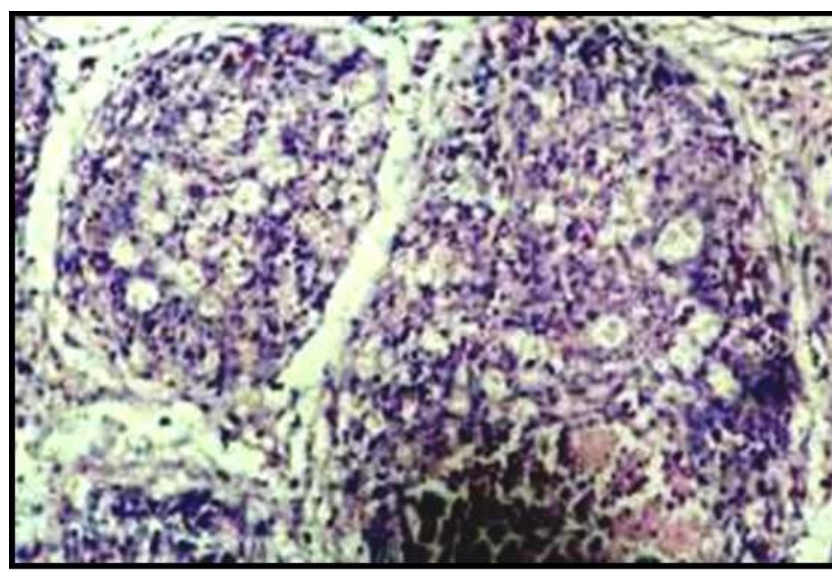

Figure 16. Section of bursa of Fabricius of a broiler chicken affected with mixed infection of IBD and Coccidiosis revealing necrosis and lymphoid depopulation in the bursal follicles HE. $x 600$

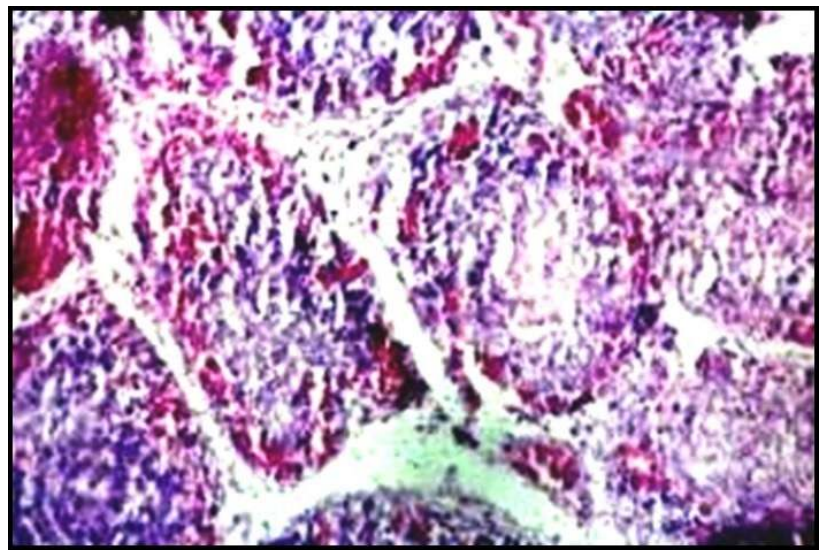

Figure 18. Section of bursa of Fabricius of a broiler chicken affected with IBD revealing haemorrhages, cellular infiltration and lymphoid cell depletion. HE. $x 400$

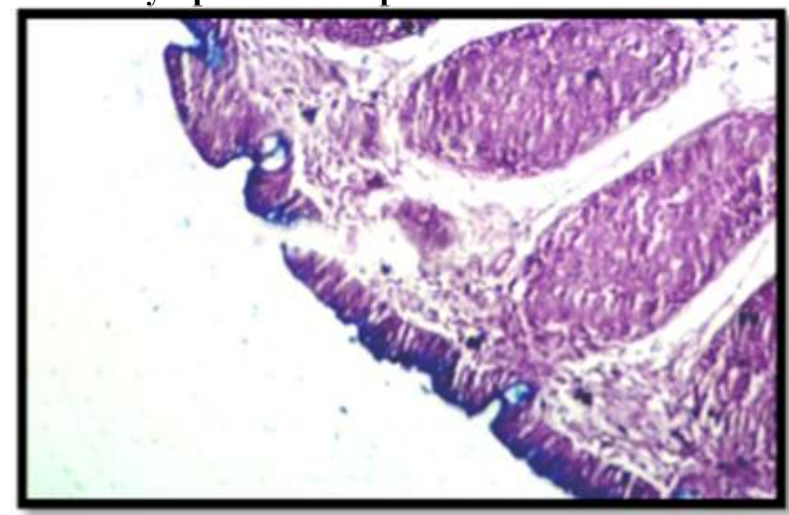

Figure 20. Section of bursa of Fabricius of a broiler chicken affected with Infectious bursal disease revealing the plical epithelium positive for acid mucopolysaccharides. Combined Alcian blue PAS. x600 


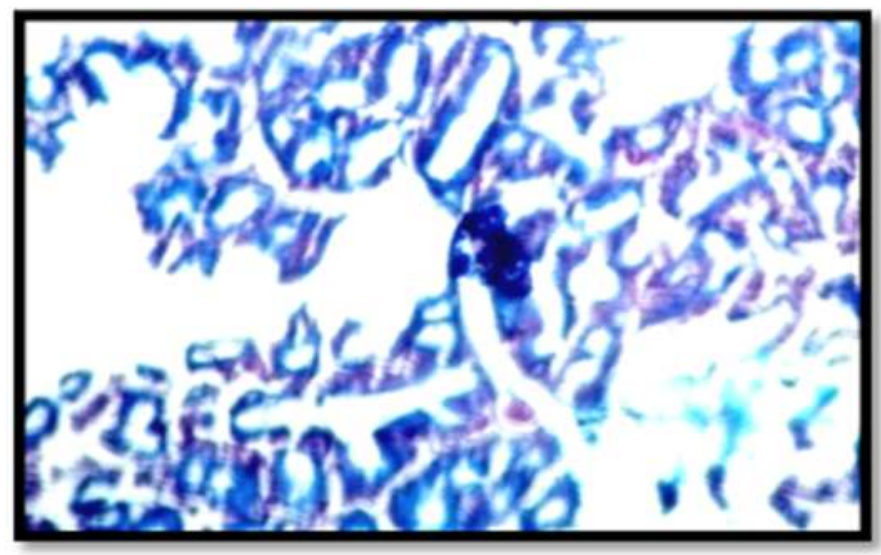

Figure 21. Section of Harderian gland of a broiler chicken affected with Infectious bursal disease revealing the alveolar epithelium positive for acid mucopolysaccharides. Combined Alcian blue PAS. x500

\section{DISCUSSION}

Grossly, in all the IBD infected groups most of the changes were observed in the bursa of Fabricius. The bursa was enlarged in all the groups, but however, if we compare among different groups, it was haemorrhagic with dark red discolouration in severely affected birds (probably infected with highly virulent strain) and in some group's bursa was found to be enlarged, filled with catarrhal exudate but not haemorrhagic. Singh et al. (2015) and Morla et al. (2016) reported similar changes in the birds affected with IBD. Now on comparing groups on the basis of different age groups, both morbidity and mortality was mostly observed in birds of 21-30 day age group. More pathogenicity in older groups may be well correlated with maternal antibody titres and vaccination status of birds. Sufficient maternal antibodies may protect birds from the disease during first few weeks of life and if birds receive timely vaccination during this period, chances of disease occurrence in birds of more than 3 weeks of age would be reduced. Our observations are found to be in accordance with the earlier reports of Rashid et al. (2013) and Preeti et al. (2018). However, the presence of concurrent infection of IBD and Coccidiosis in one of the groups is most probably attributed to the immunosuppressive effect of virus which results in the flaring up of secondary infections (Murmu et al.,2014) or can also be due to mild immunosuppressive effect of vaccine as earlier explained by Mekuriaw et al. (2017).

In this study, all the vaccinated flocks were found to be affected by the disease. The vaccine was administered through drinking water on 13th day of age in all the affected groups. There are number of reasons that can be responsible for IBD to occur in vaccinated flocks like poor vaccination practices, non-maintenance of cold chains during transport and at farm, low maternal antibody levels, use of chlorinated water during vaccination and exposure of vaccine vials to sunlight for longer duration. In these conditions, the vaccine may not be able to elicit desired level of antibodies and therefore, such flocks though vaccinated, may behave as unvaccinated flocks and thus would be highly prone to the disease. Antigenic variation within the causative agent can also lead to the vaccination failures as the vaccines will not be able to generate the desired immune response (Mohamed et al., 2014). Another and most imperative factor responsible for vaccination failures may be the emergence of new virulent strains due to the high mutation rates of virus (Morla et al., 2016). The day of vaccination, age at which vaccination is being done and the number of vaccines can also determine the elicitation of desired antibody titre against the disease, as some of the earlier findings (Pooja et al., 2017) reveal the need of first vaccination at $9^{\text {th }}$ day and the second booster vaccination at $16^{\text {th }}$ day of age for the proper prevention of disease occurrence.

No bursal atrophy was found in the present study as reported by various workers (Bejo et al., 2004; Khan et al., 2009), thus indicating that the disease had started recently because bursal atrophy is detected in advanced cases of IBD. Islam and Samad (2004) also reported muscle haemorrhages in some birds. The presence and absence of muscle haemorrhages particularly in the pectoral muscles was also found to be associated with the virulence of the virus strain as we have found these only in the severely affected groups where the Bursa of Fabricius was also found haemorrhagic. The caecal tonsils, spleen and thymus were enlarged, congested and haemorrhagic, thereby confirming the reports of Haghighi et al., (2009) who observed almost similar changes in these organs in IBD affected birds. The haemorrhages in bursa and in other lymphoid organs in IBD has been suggested as an immune mediated damage to the blood vessels which is mainly due to the effect of macrophage derived tumor necrosis factor (TNF) and interleukins or due to 
disseminated intravascular coagulation (DIC) (DosSantos et al., 2004).

Histopathologically, the lymphoid depletion, follicular necrosis, cellular infiltration, congestion and epithelial desquamation were observed in bursal follicles (Hoque et al., 2001; Rudd et al., 2001; Islam et al., 2008; Li et al., 2015) and in bursal follicles, lymphoid depletion was observed, with mild depletion in few groups to severe depletion in groups (affected with highly virulent strains) of birds affected with IBD have been reported. Degenerative changes of the bursal epithelium have also been reported by (Tanimura et al., 1995; Guvenc et al., 2004; Sellaoui et al., 2012). Thymus, spleen and caecal tonsils showed congestion, cellular infiltration, lymphoid depletion and harderian gland revealed alveolar narrowing, slight lymphoid depletion and epithelial desquamation. Similar changes in these organs have also been reported by (Tanimura et al., 1995; Rautenschlein et al.,2001; Williams and Davison, 2005).

Phosphatases are enzymes found in various tissues of animals and are involved in the hydrolysis of organic phosphate esters. The optimal activity of alkaline phosphatase is observed at high $\mathrm{pH}$ and that of acid phosphatase at low $\mathrm{pH}$ (Bancroft, 1975). Acid phosphatise is a lysosomal enzyme, mainly present within neutrophills and macrophages (Cheville, 1989). Scantly high acid phosphatase in bursa, caeca and in alveolar epithelium of Harderian gland might be due to increased infiltration of neutrophills. Also, there would have been increased production of lysosomal enzymes on immune complex phagocytosis by leakage from dead neutrophills during phagocytic vacuole formation and also due to reverse endocytosis (Tizard, 1988). Alkaline phosphatase however belongs to a group of enzymes having restricted distribution in tissues. It catalyses dephosphorylation of adenosine triphosphate (ATP) and has a role in absorption and transport of ions across the cell membrane (Danielli, 1959). Alkaline phosphatase is also found in the secondary granules of neutrophills (Cheville, 1989), thus justifying the fact of more Alkaline phosphatases in bursa, harderian gland caecal tonsils.

Among various lymphoid organs, glandular epithelium of caeca, plical epithelium of bursa and alveolar epithelium of Harderian gland were found positive for increased acid mucopolysaccharides. Many researchers have reported that increased secretion of mucopolysaccharides in and around the lesions could be due to the extended irritative action of insults and inflammatory process is responsible for qualitative increased in mucopolysaccharides (both acid and neutral) (Raekalio, 1970; Darzi et al., 2003; Shah, 2009). Increase (qualitative) in mucopolysaccharides and neutral mucopolysaccharide in basement membrane acts as a local reaction for defense (Darzi et al., 2003). Another study corroborates with the findings of present study as they reported that in intestines there were many positive acid glycol conjugate staining mucus cells near the parasitic attachment site compared to uninfected ones (Dezfuli et al., 2010). As mucopolysaccharides have an inflammatory role and also result from extended irritative action of insults, this justifies their hypersecretion (Lupu et al., 1959).

Conclusion: It could thus be concluded that IBD had prominent effect on Bursa of Fabricius in broiler chicken. There was a useful impact of histoenzymatic and histochemical techniques in prompt diagnosis of IBD. To prevent the set back of poultry sector due to various immunosuppressive diseases like IBD, the immunodiagnostics need to be developed further for timely diagnosis of the disease.

Authors' Contributions: All authors equally contributed to the manuscript and drafted, read, and approved the final manuscript.

Conflict of Interest Declaration: The authors declare that they have no competing interests.

\section{REFERENCES}

Bancroft, J.D., and M. Gamble (2002). Theory and Practice of Histological Techniques, $5^{\text {th }}$ edition. Harcout Publishers Limited, London. 181-182 p.

Bancroft, J.D. (1975). Histochemical techniques. 2nd ed. Butterworths London. 617-690 p.

Bejo, H., L.W. Tee, and U. Chulan(2004). Response of gut associated lymphoid tissue of chickens (GALT) to very virulent IBD virus of Malaysian isolate. J. Anim. Vet. Adv. 3: 142-147.

Bell, J.G. (2009). Factors limiting production efficiency and profitability from smallholder poultry production. World's Poult. Sci. J. 65: 207-210.

Cheville, N.S. (1989). Cell pathology $2^{\text {nd }}$ ed. Lowa State University Press, U.S.A., pp. 867-945.

Danielli, J.F. (1959). Cytochemistry: A critical approach. Chapman and Hall-London.

Darzi, M.M., M.S. Mir, S.A. Kamil, N. Nashiruddullah, and Z.H. Munshi (2003). Pathological changes and local defense reaction occurring in spontaneous hepatic coccidiosis in rabbits. World Rabbit Sci. 15: 23-28.

Dezfuli, B.S., F. Pironi, and A.P. Campisi (2010). The response of intestinal mucous cells to the presence of enteric helminths: their distribution, histochemistry and fine structure. J. Fish Dis. 33: 481-488.

Dos-Santos, B.M., M.P. Moraes, P.R. Barrios, S.Y. Marín, and W.M. Nascimento (2004). Occurrence of infectious bursal disease post vaccination with low passage attenuated vaccine. Arch. Inst. Biol. Sao Paulo 74: 511513. 
Gurr, E. (1958). Methods of Analytical Histology and Histo-chemistry. Leonard Hill Books Limited, 9 Eden Street, London, N.W.I.

Guvenc, T., R. Hazıroglu, M. Yarım, and R. Tunca (2004). Diagnosis of infectious bursal disease by immunoperoxidase technique Vet. J. Ankara Univ. 51: 237-238.

Haghighi, S.Z.M., A. Tavasoly, A. Shoshtary, M.A. Bahmaninejad, and S.H. Marjanmehr(2009). An experimental study on early pathogenesis of a very virulent isolate of infectious bursal disease virus, employing immunohistochemistry. Iran. J. Vet. Res. 10: 125-131.

Hoque, M.M., A.R. Omar, L.K. Chong, M. Hair-Bejo and I. Aini (2001). Pathogenicity of Sspl-positive infectious bursal disease virus and molecular characterization of the hypervariable region. Avian Pathol. 30: 369-380.

Islam, M.N., S.M.H. Rashid, M.F. Hoque, M.S.B. Juli, and M. Khatun (2008). Pathogenicity of IBDV related to outbreaks in the vaccinated flocks and the causes of vaccination failure. J. Innov. Dev. Strategy 2: 22-30.

Islam, M.T. and M.A. Samad (2004). Clinicopathological studies on natural and experimental infectious bursal disease in broiler chickens. Bangl. J. Vet. Med. 2: 31-35.

Itoo, F.A., S.A. Kamil, M.S. Mir, H.M. Khan, M.M. Darzi, and A.A. Khan (2014). Occurrence of respiratory affections in commercial broilers chicken reared in Srinagar (J\&K) India. J. Vet. Adv. 4: 350-357.

Khan, R.W., F.A. Khan, I. Khan, and M. Tariq (2009). Prevalence of infectious bursal disease in broiler in District Peshawar. ARPN J. Agric. Biol. Sci. 4: $1-5$.

Kotaiah, T. (2016). Poultry Production in India - The Current

Scenario.www.fnbnews.com.http://www.fnbnew s.com/Poultry/poultry-production-in-india--thecurrent-scenario-38620.

Li, Z., X.L. Qi, X.G. Ren, L. Cui, X.M. Wang, and P. Zhu (2015). Molecular characteristics and evolutionary analysis of a very virulent infectious bursal disease virus. Sci. China Life Sci. 58: 731-738.

Lukert, P.D. and Y.M., Saif (2003). Infectious bursal disease. Diseases of Poultry. 11. Iowa State University Press, Ames, Iowa. 161-179 p.

Luna, L.G. (1968). Manual of Histologic staining methods of the armed forces. Institute of Pathology, $3^{\text {rd }}$ edition. New York, Mc Graw Hill Book Company, New York.

Lupu, N.G., D. Velican, C. Velican, and V. Olinescu (1959). The action exerted by pneumoconiotic factors upon the acid mucopolysaccharide contents of pulmonary macrophages. Brit. J. Ind. Med., 16: 244.

Mekuriaw, A., M. Bitew, E. Gelaye, B. Mamo, and G. Ayelet (2017). Infectious bursal disease: outbreak investigation, molecular characterization, and vaccine immunogenicity trial in Ethiopia. Trop. Anim. Hlth. Prod. 49: 1295-1302.

Mohamed, M.A., K.E.S. Elzanaty, B.M. Bakhit, and M.M. Safwat (2014). Genetic characterization of infectious bursal disease viruses associated with Gumboro outbreaks in commercial broilers from Asyut Province, Egypt. ISRN Vet. Sci. 1-9.

Morla, S., P. Deka, and S. Kumar (2016). Isolation of novel variants of infectious bursal disease virus from different outbreaks in Northeast India. Microbiol. Pathogenesis. 93: 131-136.

Murmu, R., N. Islam, S.B. Juli, A.S. Khan, S.M. Rashid, F.M.A. Hossain, and M.M. Rahman (2014). Pathogenicity and immunosuppressive properties of GM-97 strain of infectious bursal disease virus in commercial broiler chickens. J Adv. Vet. Anim. Res. 1: 1-7.

Nnadi, P.A. and S.O. George (2010). A cross-sectional survey on parasites of chickens in selected villages in the subhumid zones of south-eastern Nigeria. J. Par. Res. 10: 1-6.

Pooja, K., G. Narang, K. Naresh, K. Sushma, C. Rajesh, and N.K. Mahajan (2017). Estimation of age of infectious bursal disease vaccination in broiler chickens in Haryana, India. Int.J.Curr.Microbiol.App.Sci.12: 3391-3406.

Preeti, K. Suresh, B. Laxmi, Ramkaran, J. Naresh, and G. Renu (2018). Epidemiological studies on infectious bursal disease in broiler chickens in Haryana state during 2012-2015.The Pharma Innovation J. 7: 282-285.

Raekalio, J. (1970). Enzyme histochemistry of wound healing. In: Progress in histochemistry and cytochemistry Vol 1, No. 2. Eds. Robertson, N.M. and Peter, A.G., Gustav Fischer Verlang, Stuttgart, U.S.A. 2-20 p.

Rashid, M.H., C. Xue, M.R. Islam, M.T. Islam, and Y.A. Cao (2013). Longitudinal study on the incidence of mortality of infectious diseases of commercial layer birds in Bangladesh. Prev. Vet. Med. 109: 354-358.

Rautenschlein, S., H.Y. Yeh, and J.M. Sharma (2001). A comparison of the Immunopathogenesis of different IBDV strains. In: Proceeding of the II International symposium on Infectious bursal disease and Chicken infectious anaemia, Rouischholzhausen. Germany.

Rudd, M., H. Heine, L. Parede, S.I. Sapats, and J. Ignjatovic (2001). Characterization of an Indonesian very virulent strain of infectious 
bursal disease virus (IBDV). Proceeding of the II International Symposium on Infectious Bursal Disease and Chicken Infectious Anaemia, 16-20 July, 2001, Rauischholzhausen, Germany. 40-50 p.

Sellaoui, S., N. Alloui, S. Mehenaoui, and S. Djaaba (2012). Evaluation of size and lesion scores of bursa cloacae in broiler flocks in Algeria. J. Worlds Poult. Res. 2: 37-39.

Shah, I.H., (2009). Pathological and histochemical studies on paratuberculosis in goats. MVSc thesis submitted to faculty of PG studies, SKUAST-Kashmir.

Siddique, N., K.H. Naeem, Z. Ahmed, and S.A. Malik (2008). Evaluation of RT-PCR for the detection of influenza virus serotype H9N2 among broiler chickens in Pakistan. Int. J. Poult. Sci. 7: 11221127.

Singh, J., H. S. Banga, R.S. Brar, N. D. Singh, S. Sodhi, and G. D. Leishangthem (2015). Histopathological and immunohistochemical diagnosis of infectious bursal disease in poultry birds. Vet. World 8, 1331-1339.

Tanimura, N., K. Tsukamoto, K. Nakamura, M. Narita, and M. Maeda (1995). Association between pathogenicity of infectious bursal disease virus and viral antigen distribution detected by immunohistochemistry. Avian Dis. 39:9-20.

Tizard, I.R. (1988). Immunology. An introduction. $2^{\text {nd }} \mathrm{ed}$. W.B. Saunders Co., Philadelphia.

Williams, A.E. and T.F. Davison (2005). Enhanced immunopathology induced by very virulent infectious bursal disease virus. Avian Pathol. 34, 4-14.

Withers, D., J. Young, and T. Davison (2005). Infectious bursal disease virus induced immunosuppression in the chick is associated with presence of undifferentiated follicles in the recovering bursal. Viral Immunol. 17: 127-137.

Zahid, B., A. Aslam, Y. Tipu, T. Yaqub, and T. Butt (2016). Conventional and molecular detection of infectious bursal disease virus in broiler chicken. Pakistan J. Zool. 48: 601-603. 